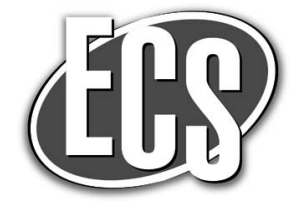

\title{
Effects of Ionomer Morphology on Oxygen Reduction on Pt
}

\author{
Jerzy Chlistunoff ${ }^{\mathrm{a}, *, \mathrm{z}}$ and Bryan Pivovar ${ }^{\mathrm{b}, *}$
}

${ }^{a}$ Los Alamos National Laboratory, Los Alamos, New Mexico 87545, USA

${ }^{b}$ National Renewable Energy Laboratory, Golden, Colorado 80401, USA

\begin{abstract}
The oxygen reduction reaction (ORR) at the interface between platinum and Nafion 1100 equivalent weight was studied as a function of temperature $\left(20-80{ }^{\circ} \mathrm{C}\right)$, humidity $(10-100 \%)$, scan rate, the manner in which Nafion film was deposited, and the state of the Pt surface using ultramicroelectrodes employing cyclic voltammetry and chronoamperometry. ORR on smooth electrodes was strongly inhibited under specific conditions dependent on temperature, humidity, and scan rate. From the data presented, we postulate that dynamic changes in the molecular structure of the ionomer at the platinum interface result in differences in ORR voltammetry for films prepared and equilibrated under different conditions. The lack of similar changes for rough, platinized electrodes has been attributed to differences in initial ionomer structure and a higher energy barrier for ionomer restructuring. These model system studies yield insight into the ionomer-catalyst interface of particular interest for polymer electrolyte fuel cells.

(C) The Author(s) 2015. Published by ECS. This is an open access article distributed under the terms of the Creative Commons Attribution 4.0 License (CC BY, http://creativecommons.org/licenses/by/4.0/), which permits unrestricted reuse of the work in any medium, provided the original work is properly cited. [DOI: 10.1149/2.0661508jes] All rights reserved.
\end{abstract}

Manuscript submitted February 10, 2015; revised manuscript received May 11, 2015. Published May 21, 2015. This was Paper 1024 presented at the Los Angeles, California, Meeting of the Society, October 16-21, 2005.

Sluggish oxygen reduction reaction (ORR) in polymer electrolyte fuel cells (PEFCs) is a bottleneck for the commercialization of PEFCs as automotive power sources. While replacing platinum as ORR catalyst in polymer electrolyte fuel cells (PEFCs) continues to be heavily pursued, ${ }^{1,2}$ the metal, in spite of its high price, still remains the catalyst of choice for commercial applications. Because of that, much effort has been made to optimize cell performance with as little platinum as possible, i.e., to maximize the utilization of platinum. ${ }^{3}$ Among various approaches to increase Pt utilization in PEFCs, the most promising are those simultaneously targeting multiple areas, where improvement is desired, e.g., Pt content in catalyst particles, strength of catalyst interaction with the support, particle agglomeration, etc. ${ }^{4-6}$ However, the accessible surface area of Pt in actual catalyst layers is always smaller than expected from the mass loading and the catalyst particle size distribution due to the agglomeration, electronic isolation, and/or ionic isolation. ${ }^{7-10}$ The ionic isolation may result from Pt particles not in contact with polymer electrolyte or Pt particles only in contact with the non-conducting regions of the polymer electrolyte. In either case, oxygen reduction reaction (ORR) cannot occur on such particles, as there is no mechanism for transporting protons to the reaction site. A few recent studies clearly demonstrate that the interfacial morphology of Nafion must play a central role in the ionic isolation of catalyst particles. Using electrochemical techniques, McGovern et al. ${ }^{11}$ demonstrated that the surface of a nano-crystalline platinum catalyst is partially blocked by Nafion. A similar conclusion was reached by Ohma et al. ${ }^{12}$ in case of smooth polycrystalline Pt surfaces. In other recent studies, ${ }^{13,14}$ it was shown that the morphology of Nafion at smooth interfaces with gas is strongly affected by ionomer hydration and that ion conduction to the surface is very heterogenous on the atomic scale with large $(\sim 100 \mathrm{~nm})$, completely insulated domains. While similar surface blocking effects could presumably also take place at the interface between ionomer and platinum in fuel cell catalyst layers, assessing this in functioning fuel cell electrodes is extremely difficult due to the complicated nature of these structures. ${ }^{15,16}$ Additionally, directly probing ionomer morphology in the catalyst layers (and more explicitly at the catalyst-ionomer interface) from e.g., small angle scattering X-ray and neutron (SAXS and SANS) measurements would be extremely challenging, if at all possible. In fact, even the present understanding of pure bulk Nafion morphology that has evolved as a result of more than 30 years of the relevant SAXS and SANS studies remains an area of debate. ${ }^{17-27}$

Due to the above challenges, a number of studies have focused on well-defined model systems under well controlled con-

*Electrochemical Society Active Member.

${ }^{\text {zE}}$-mail: jerzy@lanl.gov ditions rather than actual catalyst layers to probe the importance and investigate the impact of the Pt/ionomer interface on the oxygen reduction reaction (ORR). Among other methods, the studies employed included various spectroscopic methods, ${ }^{13,28,29}$ neutron reflectometry, ${ }^{30,31}$ computational $^{32,33}$ and electrochemical techniques. ${ }^{11,34-46}$ While the referenced studies were undertaken to elucidate fuel cell related phenomena, the actual experimental conditions sometimes differed from those typical for the fuel cell catalyst layer because of the requirements of the methodology applied. For instance, in addition to the polymer electrolyte a liquid electrolyte was used in spectroscopic ${ }^{41,42}$ and some electrochemical ${ }^{11,12}$ experiments, where the requirement of the presence of liquid water flooded Nafion which has been shown to be significantly different than water vapor equilibrated Nafion, ${ }^{47}$ and the presence of free cations likely had a strong impact on observed properties. In the majority of electrochemical studies, ${ }^{34-37,39-46}$ the platinum/ionomer interface was created by pressing a Pt ultramicroelectrode (UME) against a preformed (usually extruded) membrane. While the use of ultramicroelectrodes guaranteed virtually Ohmic-drop free results, the interfaces obtained through pressing of Pt against preformed membranes were likely strongly affected by the pre-ordered membrane structure, ${ }^{48}$ and were limited to thicker films which could affect observed performance. However, thick membranes do offer some specific advantages in these type of ORR studies. The geometry of oxygen diffusion in thick membranes remains unchanged under typical experimental conditions and therefore enables the use of a simple mass transport correction ${ }^{41,44,45}$ to extract kinetic parameters of ORR from the measured voltammograms. The application of a similar procedure for thin recast films may be sometimes questionable, since the initially "infinite" diffusion field may change to a finite one during the experiment.

A number of results obtained for ORR at the Pt/ionomer interface created by pressing an UME against a membrane have resulted in nearly steady state voltammetric behavior and two different Tafel slopes, $\sim 60 \mathrm{mV} \mathrm{s}^{-1}$ and $\sim 120 \mathrm{mV} \mathrm{s}^{-1}$, corresponding to the oxidecovered and oxide-free platinum surface. ${ }^{34-37}$ While these results are uncomplicated and somewhat expected, ${ }^{49}$ other studies indicate that ORR at the Pt/ionomer interface may actually be more complex. Electrochemical impedance spectroscopy (EIS) studies of ORR at the Pt/Nafion interface at $100 \%$ relative humidity $(\mathrm{RH})$ by Xie and Holdcroft ${ }^{46}$ demonstrated that ORR involves potential-driven changes in transport characteristics of the bulk ionomer. The authors associated these changes with the degree of flooding of the interface. ${ }^{46}$ Similarly, Parthasarathy and coworkers ${ }^{35}$ observed a significant suppression of double layer capacity of Pt in contact with Nafion upon the reduction of platinum oxide, but the effect was attributed to the adsorption of impurities, even though the Nafion membrane used in the study had been thoroughly purified. Earlier Los Alamos National Laboratory 
studies $^{38}$ demonstrated exceptionally strong inhibition of ORR at the $\mathrm{Pt} /$ recast Nafion interface at $100 \% \mathrm{RH}$ that increased with temperature. As opposed to the Parthasarathy's study, ${ }^{35}$ the inhibition was not attributed to impurities, but rather to the dehydration of Nafion at elevated temperatures and the resultant blocking of the Pt surface by the hydrophobic component of Nafion. A similar suggestion was also put forward by Mitsushima and coworkers, ${ }^{43}$ who explained the suppression of hydrogen adsorption/desorption on Pt UME pressed against different ionomeric membranes by the blocking of Pt surface sites by the hydrophobic component of the ionomer. The already complex issue of Nafion surface morphology is additionally complicated by the various effects of materials in contact with the ionomer surface. ${ }^{31,50-54}$

The goal of the work presented here is the elucidation of the effects of various factors, including temperature and relative humidity, on ORR at the interface of platinum with Nafion under well-defined and controlled conditions. While being aware of potential complexities, we decided to explore the interfaces of Pt with recast ionomer films. Such films form spontaneously and therefore are expected to more closely resemble the interfaces in actual catalyst layers than those created by contacting a Pt electrode with a preformed membrane, which exhibits microstructural orientation resulting from the manufacturing process. ${ }^{48}$

\section{Experimental}

Nafion 1100 equivalent weight (EW 1100) solution was obtained from Ion Power.

The working electrode was a $100 \mu \mathrm{m}$ diameter platinum microdisk electrode (Bioanalytical Systems). Before use, the microelectrode was polished with $0.25 \mu \mathrm{m}$ diamond paste (Buehler) and $0.05 \mu \mathrm{m}$ alumina (Buehler) and sonicated in deionized water (Millipore). The actual surface area of the microdisk was determined before every experiment from hydrogen adsorption measured by cyclic voltammetry in $0.5 \mathrm{~mol} \mathrm{dm}^{-3} \mathrm{H}_{2} \mathrm{SO}_{4}$ and subsequently used to determine the surface area changes resulting from the presence of Nafion on the surface. The roughness factor determined from the hydrogen adsorption charge was typically around 1.8. Cyclic voltammetry ensured impurities were removed from the platinum surface before depositing the ionomer film. Following multiple potential cycling between $0 \mathrm{~V}$ and $+1.4 \mathrm{~V}$, the microelectrode in the reduced surface state was removed from solution, promptly rinsed with deionized water and excess water was removed with a stream of ultrahigh purity argon.

In some experiments, platinized UMEs (100 $\mu \mathrm{m}$ diameter) were used. These were prepared by electrodepositing platinum black onto a freshly prepared Pt microdisk at a constant current of $2 \mu \mathrm{A}$ for not less than 6 minutes using a $0.05 \mathrm{~mol} \mathrm{dm}^{-3}$ chloroplatinic acid solution in $1.0 \mathrm{~mol} \mathrm{dm}^{-3} \mathrm{HCl}$ containing $0.1 \mathrm{mmol} \mathrm{dm}^{-3}$ of lead acetate. As for the smooth electrodes, the actual surface areas of the platinized electrodes were determined from hydrogen adsorption (underpotential deposition, UPD) in a $0.5 \mathrm{~mol} \mathrm{dm}{ }^{-3} \mathrm{H}_{2} \mathrm{SO}_{4}$ assuming a charge density of $210 \mu \mathrm{C} \mathrm{cm}$. The initial roughness factor of the platinized electrodes was not less than 400 and as high as 600 in some experiments with potential cycling between $0 \mathrm{~V}$ and $+1.4 \mathrm{~V}$ at $100 \mathrm{mV} \mathrm{s}^{-1}$ resulting in a decrease of the roughness factor. Potential cycling was conducted until measured currents did not noticeably change from cycle to cycle. While the decision on what changes were noticeable was somewhat arbitrary, the roughness factor corresponding to this condition was typically around 360 . Based on hydrogen UPD, an electrode with initial roughness factor of 560 lost approximately $18 \%, 9 \%, 5 \%$, and $2 \%$ of its initial electrochemical surface area during four subsequent 20 cycle-runs.

To prepare the recast ionomer film, the cleaned and polished ultramicroelectrode was held with the electrode pointing up and a small volume (between 1.3 and $8 \mu \mathrm{l}$ ) of $5 \%$ Nafion solution was deposited onto the glass/Pt electrode tip with a micropipette. Then, the electrode was placed in a small volume $\left(\sim 10 \mathrm{~cm}^{3}\right)$ chamber filled with dry $(\sim 0 \%$ relative humidity (RH)), ultrahigh purity (UHP) argon. The confined space inside the chamber guaranteed a slow rate of evaporation of the solution, which resulted in the formation of a smooth film. The films were dried in the chamber for at least three hours. Longer drying times were found to have no effect on the results of electrochemical measurements. In the initial phase of this study, Nafion films were dried in air. The quick evaporation of solvents under such conditions resulted in non-uniform films and a substantially different electrochemical behavior than that of the films evaporated in the drying chamber. The differences between these samples and the origins of the observed behavior will be discussed later.

Measurements of recast film thickness and morphology were performed on electrodes prepared in an identical fashion with those used in the electrochemical tests using a Dektak 8 stylus profiler (Veeco Instruments). Before the measurement, the film was cut through the center with a razor blade and half was removed to expose the glass/platinum surface. The films examined by profilometry were not cured/conditioned in any way and the measurements were performed in a clean room at an ambient temperature $\left(\sim 19{ }^{\circ} \mathrm{C}\right)$ and low relative humidity $(\sim 10 \%)$. No profilometry was measured for the platinized electrodes, but optical microscopy indicated that the film surface was slightly elevated in the area above the Pt disk.

The electrochemical cell employed was prepared as follows. The ionomer coated UME was removed from the drying chamber and ribbons made of Nafion 117 membrane and Pt were placed along opposite sides of the glass body of the electrode. These ribbons were secured with Teflon tape and electrolytic contacts between the ribbons and the film were made using small quantities of Nafion solution. In the "minicell" thus produced, the platinum ribbon served as a counter electrode and the Nafion ribbon acted as an electrolytic bridge between the external reference electrode and the working electrode. In order to find out whether a non-uniform current distribution resulting from such cell geometry could affect experimental results, in a single experiment, the counter electrode was made of a Pt wire that encircled the UME. As the modified geometry of the minicell did not result in meaningful changes of the measured ORR currents and it was significantly more difficult to implement, the more simple approach described above was employed.

Subsequently, the minicell was connected to the external reference electrode chamber and to the counter electrode lead wire (Fig. 1) and placed in a controlled humidity chamber, where it was first cured for 24 hours in argon atmosphere at $\sim 10 \% \mathrm{RH}$ provided by a saturated $\mathrm{LiCl}$ solution and then equilibrated for 20 hours at the desired

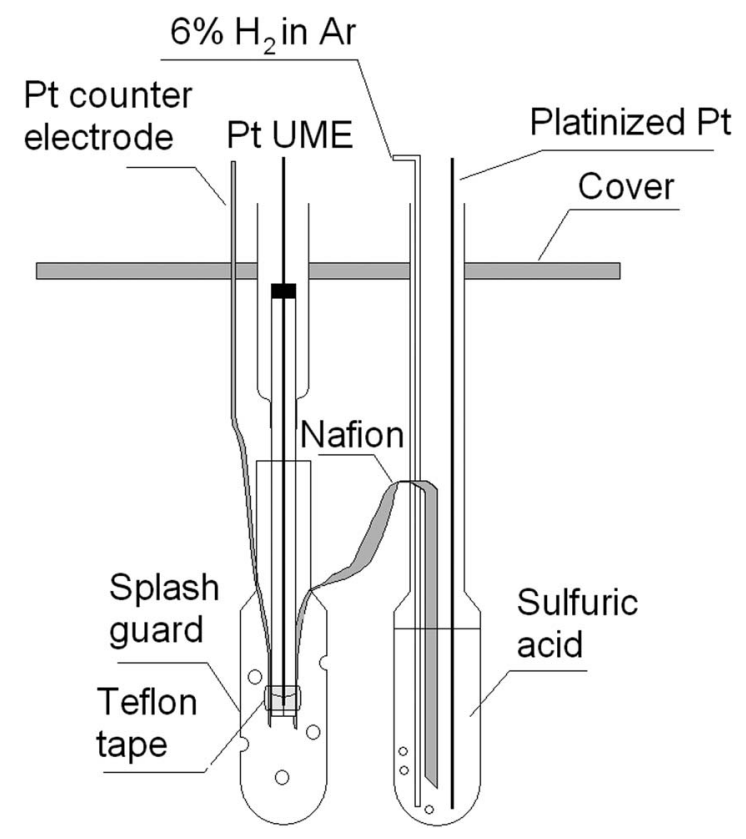

Figure 1. Electrochemical minicell with a recast ionomer film as the electrolyte. 
temperature and relative humidity. The external reference electrode consisted of a platinized platinum wire immersed in a $0.5 \mathrm{~mol} \mathrm{dm}^{-3}$ $\mathrm{H}_{2} \mathrm{SO}_{4}$ solution in equilibrium with forming gas, consisting of $6 \% \mathrm{H}_{2}$ in Ar. The equilibrium potential of the reference electrode, hereafter called FGHE (forming gas hydrogen electrode) was $+39 \mathrm{mV}$ versus RHE in a $0.5 \mathrm{~mol} \mathrm{dm}^{-3} \mathrm{H}_{2} \mathrm{SO}_{4}$ (at the sea level ${ }^{55}$ ).

Lithium chloride (Fisher) solutions of various concentrations were used to control the relative humidity during film equilibration and measurements. In order to attain desired humidity, gas (argon or oxygen) was slowly purged through two large equilibrating bubblers filled with $\mathrm{LiCl}$ solution or deionized water before entering the controlled humidity chamber partially filled with the same solution/water. The first equilibrating bubbler was equipped with a fine gas dispersion tube. During the equilibration and the measurements, the bubblers and the controlled humidity chamber were immersed in a controlled temperature water bath that was covered with a thermally insulating material. In order to reduce electromagnetic noise during the measurements, the outer surface of the bath was covered with a fine aluminum mesh connected to ground.

Cyclic voltammetry and chronoamperometry measurements were carried out with an EG\&G PAR Model 283 potentiostat interfaced to a personal computer. In order to provide a consistent electrode pretreatment for every experiment, the following procedure was used. The potential of the UME was initially scanned between the onset of hydrogen evolution and $\mathrm{Pt}$ oxide formation in $\mathrm{Ar}$ at a scan rate of $100 \mathrm{mV} \mathrm{s}^{-1}$, until a steady state voltammogram was obtained. The suitable potential limits were $+1.4 \mathrm{~V}$ and $0 \mathrm{~V}$, adjusted for the variable junction potential effects in low water activity samples. Once a steady state background current was obtained, single cycle voltammograms at different scan rates were recorded. The cycle started with the microelectrode being held for $10 \mathrm{~s}$ at the respective anodic potential limit (usually 1.4 V), after which time the potential was scanned cathodically at a given scan rate (usually $5 \mathrm{mV} \mathrm{s}^{-1}$ ) to the cathodic potential limit (usually $0 \mathrm{~V}$ ) and then back to the anodic limit. The background currents recorded in this way were further subtracted from the measured ORR currents recorded under identical conditions. In chronoamperometric experiments, the microelectrode was similarly held for $10 \mathrm{~s}$ at the identical anodic potential (usually $1.4 \mathrm{~V}$ ) and then the potential was changed stepwise to a desired value. The same procedure was used to record both background and ORR currents.

\section{Results and Discussion}

Film morphology and thickness. - Film morphology and thickness were found to depend strongly on the conditions of film preparation. The surface of films obtained by quick solvent evaporation in $\sim 10$ $20 \% \mathrm{RH}$ air were rough and film thickness was non-uniform (Fig. 2a).
On the contrary, films produced by slow evaporation of the casting solution in the drying chamber apparatus filled with $\sim 0 \% \mathrm{RH}$ UHP argon were smooth and the thickness of the film over the $100 \mu \mathrm{m} \mathrm{Pt}$ disk was relatively uniform (Fig. 2b). As seen in Fig. 2b, at $\sim 0 \%$ RH, Nafion had a tendency to accumulate at the perimeter of glass body of the electrode, but when a drop of water was put at the bottom of the drying chamber $(\sim 100 \% \mathrm{RH})$ Nafion instead accumulated at the very center of the electrode (not shown). Consequently, the film thickness in the central portion of the electrode, where the Pt disk was located, was $13.5 \pm 0.6 \mu \mathrm{m}$ for $8 \mu \mathrm{l}$ of Nafion solution at $\sim 0 \% \mathrm{RH}$ (Fig. $2 \mathrm{~b}$ ), whereas the dome shaped "film" obtained at $\sim 100 \%$ RH covered no more than $20 \%$ of surface area of the glass electrode body and was approximately $200 \mu \mathrm{m}$ thick at its highest point, as determined by ordinary optical microscopy.

The change in film morphology that accompanies the increase in $\mathrm{RH}$ implies that hydration of the bulk ionomer is thermodynamically preferred over hydration of the surface layer of ionomer. This finding remains in agreement with hydrophobicity of Nafion surface, ${ }^{56}$ which has been frequently invoked as the origin of the so called Schroeder's paradox, ${ }^{47,57,58}$ i.e., the inability of Nafion and some other polymeric materials to achieve the state of full hydration when in contact with $100 \% \mathrm{RH}$ water vapor, in spite of the water activity in the gas phase being unity.

For the purpose of the present work, we selected Nafion films evaporated at $\sim 0 \% \mathrm{RH}$. While the thickness $(\leq 13.5 \mu \mathrm{m})$ of such films significantly exceeded that in typical fuel cell catalyst layers, it guaranteed high mechanical strength of the film and the accurate determination of its thickness. The likely organized bulk structure of such films might have rendered the interactions of the polymer with Pt less effective in determining the interfacial film morphology. Therefore, any and all changes in that morphology induced by changes in the oxidation state of Pt surface presented in the following sections must have resulted from the existence of real and strong driving forces. With only a few exceptions clearly defined in the text below, the initial interfacial morphology of the studied Nafion films corresponded to non-oxidized or negligibly oxidized Pt surface.

Smooth Pt surface. Voltammetry in $\mathrm{O}_{2}$ free environment.- CVs obtained in ultrahigh purity argon, were recorded to evaluate the impact of potential impurities on our UME studies and compare response of different UMEs. Relevant voltammograms are shown in Figure 3. As described in the Experimental section, the voltammograms were recorded for Nafion films equilibrated for $20 \mathrm{hrs}$ in $\mathrm{O}_{2}$ free atmosphere and their initial interfacial morphology was imposed by these conditions.

As a phase separated polymer, Nafion is expected to block hydrogen adsorption (underpotential deposition, UPD) sites on Pt surface,

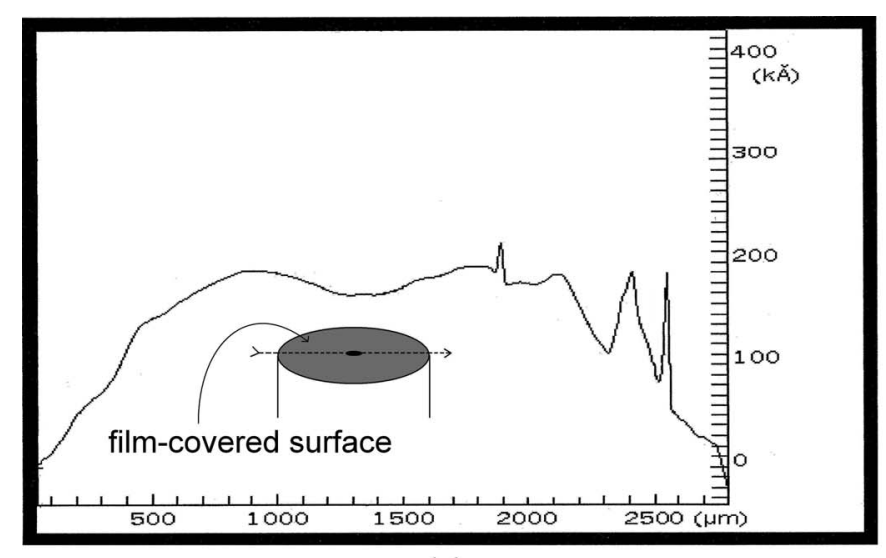

(a)

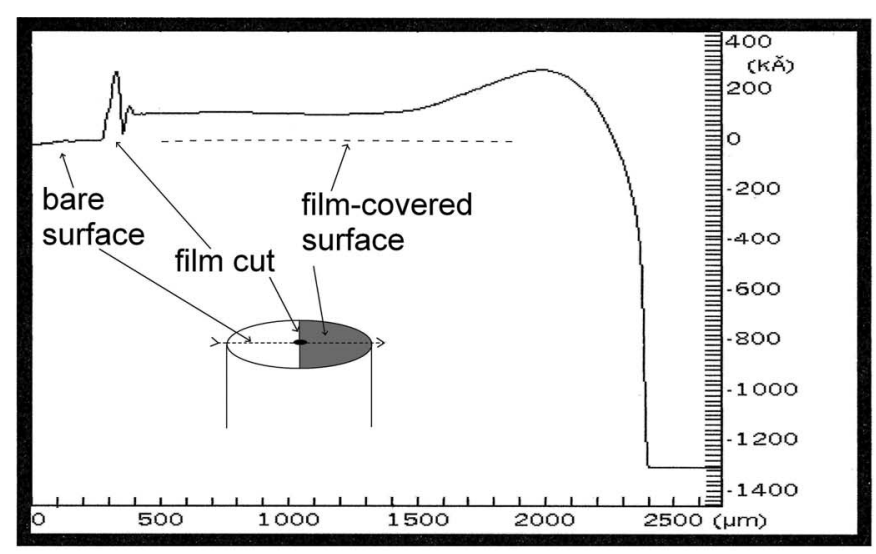

(b)

Figure 2. Profilometry of films prepared by depositing 5\% Nafion solution onto the tip of a glass-encapsulated $100 \mu \mathrm{m}$ Pt UME ( $\sim 3.5 \mathrm{~mm}$ diameter). The arrows indicate the path of the profilometer stylus. (a) Uncut film prepared by dipping the tip of the UME in Nafion solution and drying in air. (b) $8 \mu 1$ of Nafion solution deposited onto the UME tip and dried in apparatus shown in Fig. 1 at $\sim 0 \% \mathrm{RH}$. 


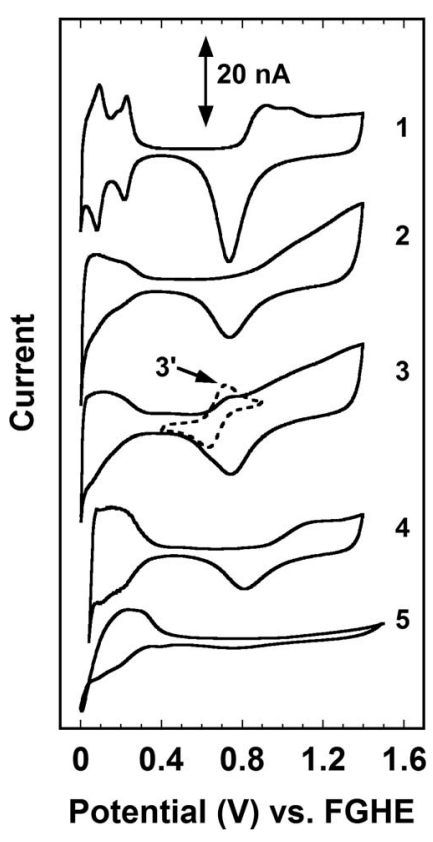

Figure 3. Voltammetry of a $100 \mu \mathrm{m}$ Pt UME in contact with sulfuric acid and Nafion at $20^{\circ} \mathrm{C}$ in ultrahigh purity $\mathrm{Ar}$ free of molecular oxygen. Scan rate $100 \mathrm{mV} \mathrm{s}^{-1}$. (1) $0.5 \mathrm{~mol} \mathrm{dm}^{-3} \mathrm{H}_{2} \mathrm{SO}_{4}$; (2) $13.5 \mu \mathrm{m}$ thick Nafion film equilibrated with liquid water; (3) $13.5 \mu \mathrm{m}$ Nafion at $100 \% \mathrm{RH}$; (3') Quasireversible $\mathrm{Fe}^{3+/ 2+}$ red-ox system in Nafion at $100 \% \mathrm{RH}$; (4) $13.5 \mu \mathrm{m}$ Nafion film at $10 \% \mathrm{RH}$; (5) $13.5 \mu \mathrm{m}$ Nafion film at $\sim 0 \% \mathrm{RH}$.

when its hydrophobic backbone comes in contact with the metal, whereas the hydrophilic component should promote hydrogen UPD the same way as in aqueous electrolyte solutions. Water in the hydrophilic phase facilitates proton transfer to $\mathrm{Pt}$ surface $\left(\mathrm{Pt}+\mathrm{H}_{\mathrm{aq}}{ }^{+}+\right.$ $\left.\mathrm{e}^{-} \rightarrow \mathrm{PtH}\right)$ and the respective charge of hydrogen UPD should be directly proportional to the actual $\mathrm{Pt}$ surface area in contact with the hydrophilic Nafion component. Consequently, in absence of specific interactions between Nafion and Pt, the hydrogen UPD will increase with ionomer hydration, which improves with $\mathrm{RH}$ but decreases with temperature. Slightly different behavior can be expected for Pt oxide formation. The oxide formation is kinetically controlled and water is consumed in the reaction $\left(\mathrm{Pt}+\mathrm{H}_{2} \mathrm{O} \rightarrow \mathrm{PtO}+2 \mathrm{H}^{+}+2 \mathrm{e}^{-}\right)$. Therefore, the extent of Pt oxidation is determined not only by the contact surface area between the hydrophilic Nafion component and Pt but also by the actual reaction kinetics, which depends on the free energy of water in the polymer. The kinetics is expected to improve with temperature and the overall ionomer hydration. As mentioned above, the latter increases with RH but decreases with temperature.

As manifested by the loss of well-defined hydrogen UPD peaks and the decrease in their surface areas (curve 1 vs. curve 2, Fig. 3), hydrogen adsorption on a smooth Pt surface is suppressed in the presence of Nafion film. The effect was found to increase with a decrease in scan rate, which indicates a transient character consistent with blocking or obstruction of catalyst sites. The kinetic character of the Pt surface blocking together with the limited accuracy of the determination of the significantly suppressed hydrogen UPD charges made it impossible to determine the effects of temperature and $\mathrm{RH}$ on the equilibrium surface accessibility. The relative extent of surface blocking under specific and identical time constraints for all experimental conditions could be estimated from voltammetry recorded at a constant scan rate. We found that a scan rate of $100 \mathrm{mV} \mathrm{s}^{-1}$ offered the best overall accuracy for such determinations. However, the accuracy was still insufficient to observe well defined trends with two exceptions. First, the hydrogen adsorption at $10 \% \mathrm{RH}$ was consistently less suppressed than that at $100 \% \mathrm{RH}$ over the whole range of temperature $\left(20-80^{\circ} \mathrm{C}\right)$ (Fig. 4). Quite significant hydrogen UPD was also observed in dry Ar (nominally $0 \% \mathrm{RH}$ ), in agreement with the secondary role of water in

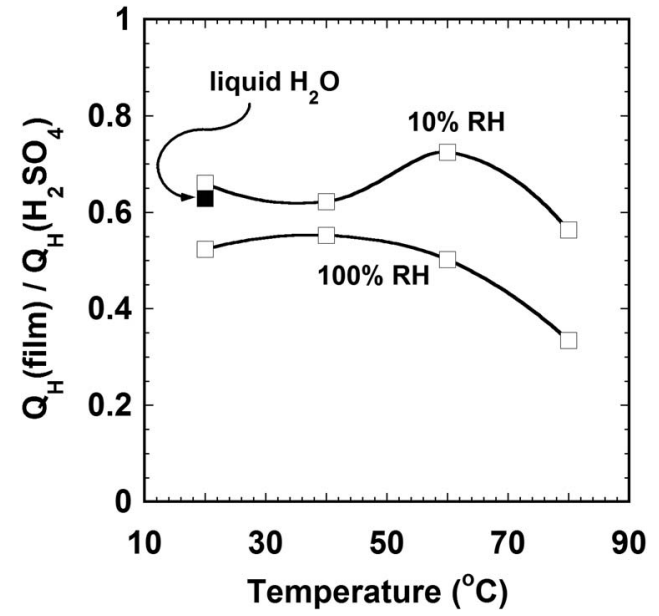

Figure 4. Steady state charges of hydrogen UPD on a $100 \mu \mathrm{m}$ Pt UME covered with $13.5 \mu \mathrm{m}$ Nafion film measured by multiple scan voltammetry following a 10 s oxidation at $+1.4 \mathrm{~V}$, normalized against hydrogen UPD charges measured for the same electrode in a $0.5 \mathrm{~mol} \mathrm{dm} \mathrm{dm}^{-3} \mathrm{H}_{2} \mathrm{SO}_{4}$ before the film deposition. Scan rate $100 \mathrm{mV} / \mathrm{s}$.

the reaction (Fig. 3, curve 5). Second, hydrogen UPD peak area was found to decrease with temperature increase from $60{ }^{\circ} \mathrm{C}$ to $80{ }^{\circ} \mathrm{C}$ at $10 \% \mathrm{RH}$ and from $40{ }^{\circ} \mathrm{C}$ to $80{ }^{\circ} \mathrm{C}$ at the remaining $\mathrm{RHs}(100 \% \mathrm{RH}$ shown in Fig. 4). The first finding indicates that the Pt/Nafion surface is more accessible, i.e., has a better contact with the hydrated Nafion component at $10 \% \mathrm{RH}$ than at $100 \% \mathrm{RH}$ and is opposite to what could be expected from the differences in the equilibrium ionomer hydration at the two humidities. It also suggests that water present in the ionomer may facilitate the processes responsible for the surface blocking.

Due to the kinetic character of the surface blocking, the interpretation of the decrease of hydrogen UPD with temperature is not simple, in spite of the apparent correlation between the blocking and the temperature driven changes in the overall ionomer hydration. Other phenomena, e.g., thermal desorption of hydrogen, competitive adsorption of impurities or incomplete $\mathrm{Pt}$ oxide reduction may have potentially contributed to the observed behavior as well. The role of thermal hydrogen desorption can be questioned, because the magnitude of the effect significantly exceeds that for the thermal desorption of hydrogen in $\mathrm{H}_{2} \mathrm{SO}_{4}$ solutions. ${ }^{59-63}$ Moreover, hydrogen adsorption/desorption on Pt in acidic media is virtually instantaneous and reversible, whereas the phenomena observed by us occur on the time scale of several seconds, i.e., it is rather the fast hydrogen UPD that follows the energetically more favorable but slower adsorption processes rather than the other way around. Due to complexities of Nafion morphology and surface thermodynamics ${ }^{47}$ and the poorly understood character of Pt-Nafion interactions, it is impossible to rule out any role of impurities in the observed phenomena. However, the large magnitude of the inaccessible (blocked) surface area cannot be linked to common impurities, especially given the long times $(20 \mathrm{~h})$ of the cell equilibration in UHP argon environment, which are expected to result in lower degrees of Nafion contamination at higher temperatures. Similarly, the observed surface blocking effects cannot be explained by an incomplete Pt oxide reduction. We found that neither the background currents presented in Fig 3 nor their slower scan rate $\left(\geq 5 \mathrm{mV} \mathrm{s}^{-1}\right)$ counterparts recorded in the ORR studies presented in the following sections were affected by the number of times or by the order in which they were recorded. This finding indicates that the Pt surface properties did not change during the experiments and rules out any accumulation of $\mathrm{Pt}$ oxide on the electrode surface. Additional evidence for the above conclusion will be presented later. Consequently, the decrease in hydrogen UPD results most likely from temperature-driven changes in Nafion morphology at the interface with Pt and reflects the tendency of the hydrophobic backbone of Nafion to occupy the 


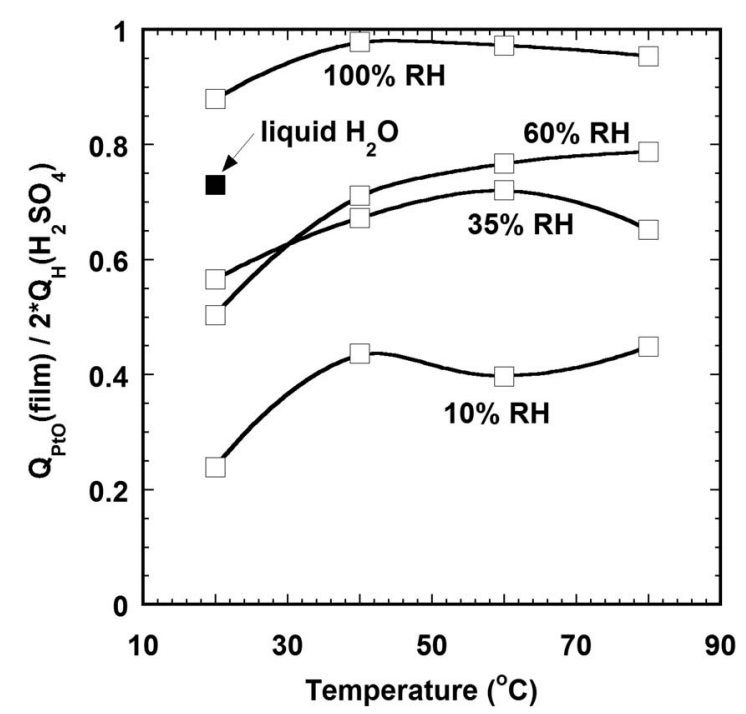

Figure 5. Charges of Pt-oxide/hydroxide reduction on a $100 \mu \mathrm{m}$ Pt UME covered with $13.5 \mu \mathrm{m}$ Nafion film measured by linear scan voltammetry following a $10 \mathrm{~s}$ oxidation at $+1.4 \mathrm{~V}$, normalized against hydrogen UPD charges measured for the same electrode in a $0.5 \mathrm{~mol} \mathrm{dm}^{-3} \mathrm{H}_{2} \mathrm{SO}_{4}$ before the film deposition. Scan rate $5 \mathrm{mV} / \mathrm{s}$.

interface between the ionomer and bare Pt surface. Indeed, the presence of a hydrophobic layer at the smooth Pt/Nafion interface in high humidity environments was demonstrated by neutron reflectometry. ${ }^{31}$ The similar tendency of Nafion to push out its hydrophobic component to the interfaces with humidified gaseous phases, ${ }^{47,56}$ has been also manifested by the profilometry in this work.

The effect of relative humidity on platinum oxide (hydroxide) formation at the Pt/Nafion interface shows an opposite trend to that of hydrogen adsorption (Fig. 5). The data in Fig. 5 demonstrate that no more than $\sim 45 \%$ of $\mathrm{Pt}$ surface can be oxidized at $10 \% \mathrm{RH}$, whereas almost $100 \%$ of Pt surface area is accessible to platinum oxide (hydroxide) formation at $100 \% \mathrm{RH}$ during a $+1.4 \mathrm{~V}$ hold for $10 \mathrm{~s}$. The surface oxidation is almost completely suppressed at $\sim 0 \% \mathrm{RH}$ (Fig. 3), since there is no unbound water inside the film under such conditions, and almost unobstructed at $100 \% \mathrm{RH}$. A similar behavior, i.e., an increase in surface availability of the hydrophilic component of Nafion with increasing RH was observed at the interface of preformed Nafion membranes with humidified oxygen/air. ${ }^{14,56}$ However, the difference between the drop cast Nafion films used in the present study and the preformed membranes ${ }^{14,56}$ is that the surface morphology of the latter is virtually fixed by the forming processes, ${ }^{48}$ whereas the former have much higher mobility. The higher mobility of the ionomer chains in the cast films is directly implied by the significant solubility of such films. ${ }^{64}$ In consequence, the interfacial hydration of preformed membranes is largely determined by their bulk hydration, whereas the surface morphology of cast films is also influenced by their surface/interfacial energy.

One has to note the presence of a reversible red-ox system at $\sim 0.7 \mathrm{~V}$ in some voltammograms shown in Fig. 3 . The red-ox system was attributed to iron impurity and had no effect on the phenomena described in this paper.

Since the voltammetric experiments demonstrated that the oxidation state of Pt surface affects the interfacial Nafion morphology, a limited number of experiments were performed with films either evaporated or cured in presence of oxygen. No striking differences in the background currents recorded for such films ${ }^{30}$ and those produced using the standard procedure (see Experimental section) could be seen. However, as will be shown below, oxygen voltammograms recorded for these films were significantly different than those obtained for the films made, cured and equilibrated using the standard procedures (see Experimental section).

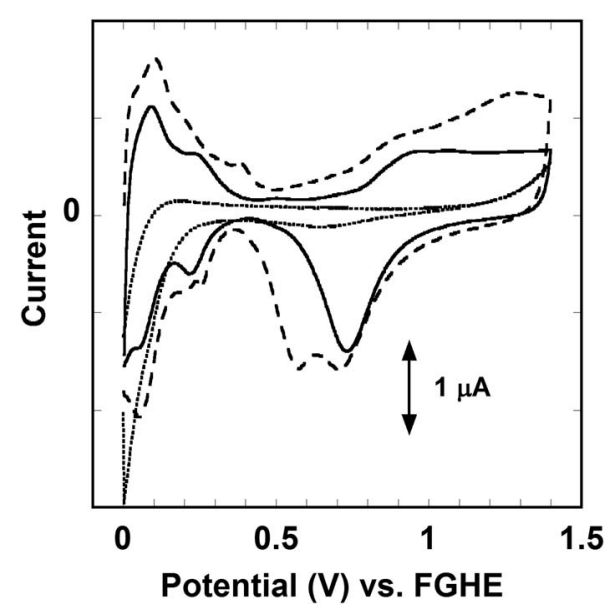

Figure 6. Multiple-cycle voltammetry of a platinized $100 \mu \mathrm{m}$ Pt UME covered with $13.5 \mu \mathrm{m}$ Nafion film in $100 \% \mathrm{RH}$ argon at $20{ }^{\circ} \mathrm{C}$. Scan rate $100 \mathrm{mV} \mathrm{s}^{-1}$. Roughness factor before film deposition - 350. Dotted line $1^{\text {st }}$ cycle; dashed line $-81^{\text {st }}$ cycle, solid line $-420^{\text {th }}$ cycle.

Background currents. Pt black surface.- As the nature of the PtNafion interface was of specific concern, we also investigated rough, platinized surfaces to compare with smooth polycrystalline Pt surfaces. The terms Pt black and platinized are used interchangeably to describe the rough Pt electrodes investigated here. Voltammograms for platinized electrodes covered with films of Nafion, recorded at $100 \% \mathrm{RH}$ and $20^{\circ} \mathrm{C}$, are presented in Fig. 6. Initial voltammograms exhibited very low Pt activity in both hydrogen adsorption/desorption and Pt oxide formation/reduction regions. The electrode activity increased after several cycles and the measured voltammograms exhibited typical Pt oxidation/reduction and hydrogen UPD features. However, other atypical oxidation and reduction peaks were also seen in the voltammmograms (dashed line in Fig. 6). The additional peaks most likely originated from the products of platinum black catalyzed oxidation of the alcohols present in the Nafion solution. As opposed to the smooth Pt electrodes, where typically no more than 50 potential scans at $100 \mathrm{mV} \mathrm{s}^{-1}$ between 0 and $+1.4 \mathrm{~V}$ were sufficient to attain the maximum surface activity, more extensive potential cycling was required to activate the Pt-black covered electrodes. Sometimes, as many as 450 cycles were required to obtain a reproducible voltammogram consistent with expected Pt features. Such extensive potential cycling results in loss of electrochemical surface area. For two reasons, the exact loss could not be determined. First, the additional peaks in the voltammograms (Fig. 6) obscure the features associated with hydrogen UPD and Pt oxidation/reduction. Second, the initial Pt surface area in contact with the hydrophilic Nafion component was unknown. After the electrochemical conditioning, the measured hydrogen adsorption/desorption and platinum oxide formation/reduction charges remained stable, i.e., they did not undergo meaningful changes within 20 potential cycles. The number of cycles required to activate the electrode decreased at higher temperatures. Higher temperatures are expected to enhance the mobility of Nafion, and increase surface desorption and volatility of potential contaminants. In general, the voltammograms recorded for the activated Pt black-covered electrodes exhibited a better defined hydrogen adsorption/desorption region (Fig. 6) than those recorded for smooth electrodes. The red-ox features associated with the $\mathrm{Fe}^{3+} / \mathrm{Fe}^{2+}$ system were obscured by significantly higher Pt-related currents.

As opposed to smooth Pt/Nafion interfaces (Fig. 5), neither hydrogen UPD nor Pt oxide formation/reduction charges on the platinized Pt electrodes were measurably changing with the scan rate between $5 \mathrm{mV} \mathrm{s}^{-1}$ and $500 \mathrm{mV} \mathrm{s}^{-1}$. Moreover, the oxidation reaction during a 10 s potential hold at $+1.4 \mathrm{~V}$ and $100 \% \mathrm{RH}$ resulted in a smaller surface coverage by PtO than that available for hydrogen adsorption (Fig. 7). This finding indicates that the morphology of Nafion layers at 


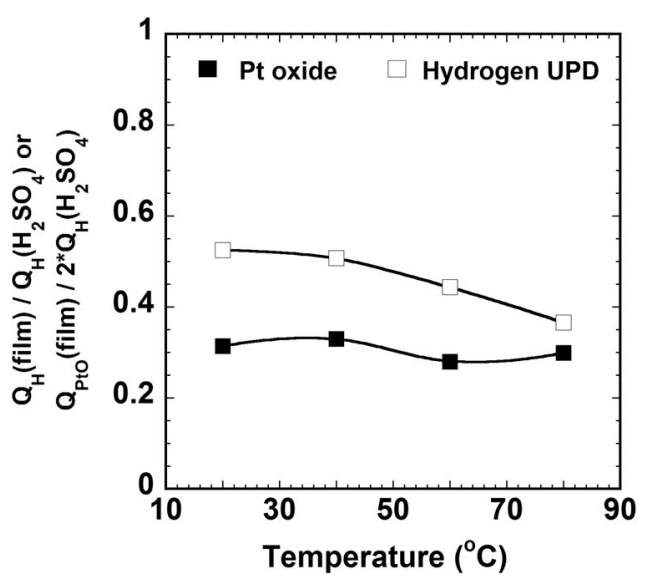

Figure 7. Charges of hydrogen UPD and Pt-oxide/hydroxide reduction on a platinized $100 \mu \mathrm{m}$ Pt UME in contact with Nafion at 100\% RH. Roughness factor before film deposition - 350. The experimental conditions for hydrogen UPD and Pt oxide measurement as in Figures 5 and 6, respectively.

smooth $\mathrm{Pt} / \mathrm{Nafion}$ interfaces enables almost unobstructed access to $\mathrm{Pt}$ surface at $+1.4 \mathrm{~V}$ and $100 \% \mathrm{RH}$, whereas the access is compromised at rough $\mathrm{Pt}$ surfaces, as manifested by the normalized $\mathrm{PtO}$ reduction charges being systematically lower than the respective hydrogen UPD charges on rough interfaces (Fig. 7). This is because the ionomer chains cannot assume the most favorable orientation/configuration around all the microscopic features of a rough surface due to the steric barriers and interactions in the bulk phase. As a result, the distribution of hydrophilic and hydrophobic domains at the "nanostructured" interface is determined to a lesser extent by their relative affinity to platinum than at smooth interfaces (polymer mobility inhibited).

The only similarity between the results obtained for platinized electrodes and smooth electrodes is that hydrogen adsorption tends to decrease slightly at higher temperatures (Figs. 5 and 7). As the hydrogen adsorption charges on Pt black were independent of scan rate, their temperature induced decrease most likely reflects the temperature induced hydrogen desorption. Similar conclusion could not be made based on the scan rate dependent, i.e., kinetically controlled, hydrogen adsorption on smooth Pt surfaces (Fig. 4).

A small decrease of platinum oxide reduction charge with temperature can also be seen for platinized electrodes (Fig. 7). As the effect is much weaker than that on hydrogen UPD (Fig. 7) and is rarely seen under other experimental conditions (Fig. 5), it most likely reflects a temperature driven decrease in overall ionomer hydration. ${ }^{65}$

ORR on a smooth Pt surface - temperature and humidity effects.Figure 8 shows ORR voltammograms recorded at four different temperatures and four different humidities and a scan rate of $5 \mathrm{mV} \mathrm{s}^{-1}$. According to a previous study, ${ }^{38}$ this scan rate is sufficiently low for steady state voltammetric behavior to develop under the experimental conditions. However, significant differences of ORR currents in the forward and reverse scans clearly demonstrate non-steady state behavior. The hysteresis observed originates from inhibition of ORR, which progresses with the duration of ORR, as also demonstrated under variable scan rate voltammetric and potentiostatic conditions (Figs. 9 and 10, respectively). Similar phenomena were previously observed for cast Nafion films, ${ }^{38}$ but have not been detected in experiments employing Pt ultramicroelectrodes pressed against preformed Nafion membranes. ${ }^{34,36,37,40,41}$ As seen in Fig. 8, ORR inhibition is also manifested by the significant changes in the voltammetric (current vs. potential) slopes. While the ORR Tafel slopes are expected to change from $\sim 60 \mathrm{mV}$ to $\sim 120 \mathrm{mV}$ per current decade with the cathode overpotential due to changes in the oxidation state of the $\mathrm{Pt}$ surface, most voltammograms in Figs. 8 and 9 exhibit significantly higher slopes.

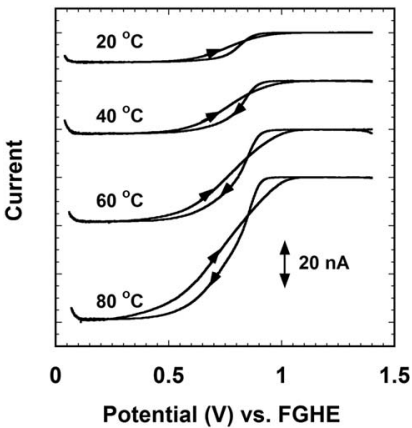

(a)

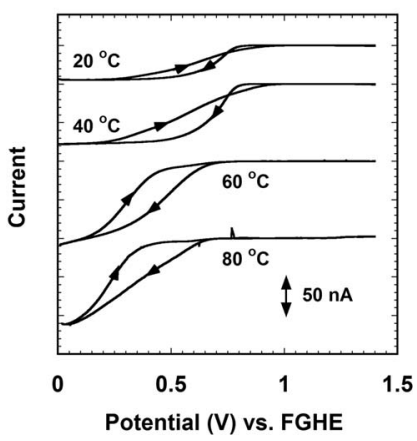

(c)

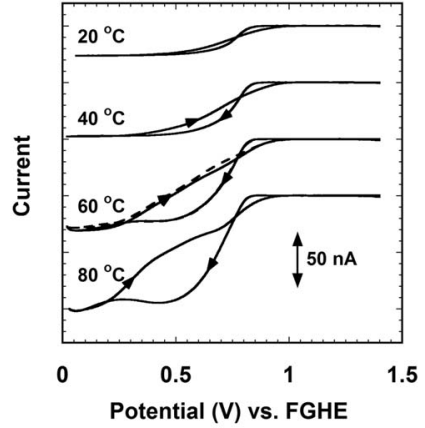

(b)

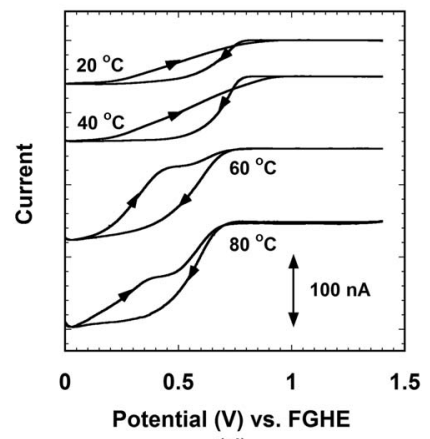

(d)
Figure 8. Background corrected voltammograms of oxygen on a $100 \mu \mathrm{m}$ Pt UME covered with $13.5 \mu \mathrm{m}$ Nafion film at different temperatures and humidities. Scan rate $5 \mathrm{mV} \mathrm{s}^{-1}$. Relative humidity: (a) $10 \%$; (b) $35 \%$; (c) $60 \%$; (d) $100 \%$. Two voltammograms from separate experiments shown in Fig. 8b demonstrate typical reproducibility of the results.

The potentiostatic transients shown in Fig. 10 demonstrate that relatively short times are sufficient to cause a decrease in ORR current even at very low (highly reducing) potentials $(\leq+0.3 \mathrm{~V}$ vs. FGHE). If neither the charge transfer kinetics nor the film properties changed during the reduction, the ORR current at high overpotentials would be determined exclusively by diffusion. The oxygen diffusion would be very fast and virtually planar at very short times, but would gradually slow down and become partially spherical following the expansion of the diffusion layer. These changes are best described by the Shoup and Szabo equation ${ }^{66}$ and expected to produce an approximately linear decrease of current with the inverse square root of time. The current decline would continue until the expanding diffusion layer reached

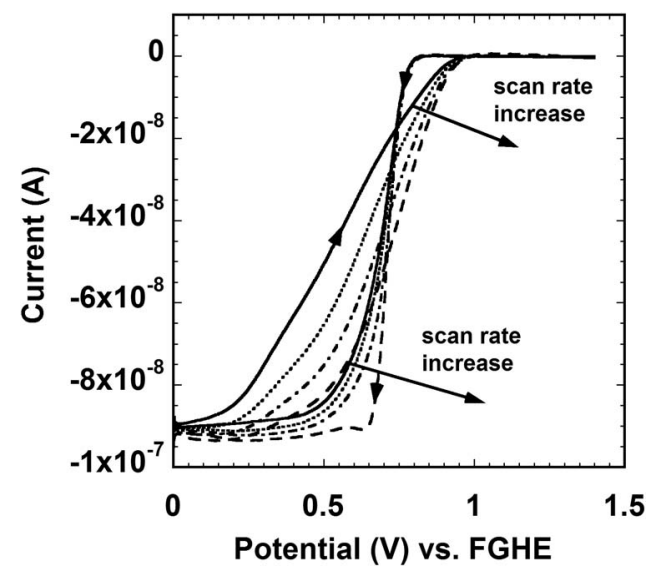

Figure 9. The effect of scan rate on the background corrected voltammetry of oxygen on a $100 \mu \mathrm{m}$ Pt UME covered with $13.5 \mu \mathrm{m}$ thick Nafion film at $40{ }^{\circ} \mathrm{C}$ and $100 \%$ RH. Scan rates: $5 \mathrm{mV} \mathrm{s}^{-1}$ - solid line; $10 \mathrm{mV} \mathrm{s}^{-1}$ - dotted line; $20 \mathrm{mV} \mathrm{s}^{-1}$ - dashed dotted line; $50 \mathrm{mV} \mathrm{s}^{-1}$ - dashed line. 


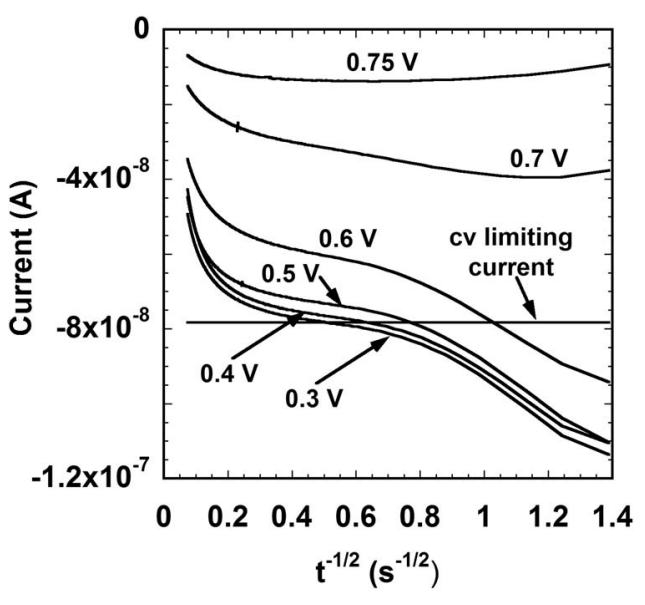

Figure 10. Background corrected chronoamperometry of oxygen on a 100 $\mu \mathrm{m}$ Pt UME covered with $13.5 \mu \mathrm{m}$ thick Nafion film at different reduction potentials. RH $60 \%$. Temperature $40^{\circ} \mathrm{C}$.

the film boundary. The major component of the diffusion would become planar again, but this time it would be determined by the limited diffusion field (film thickness). Under such conditions, both the planar and the remaining spherical component of diffusion would contribute to a virtually constant (steady state) current. For a limited time, the currents measured at high overpotentials for the Nafion coated electrode (Fig. 10) exhibit the expected behavior, i.e., an approximately linear current decrease at short times is followed by a plateau region in close agreement with the limiting current from the voltammograms. However, the steady state current cannot be maintained and longer reduction times result in further current decline, in agreement with the Pt surface blocking hypothesis. The results shown in Fig. 10 indicate once again that no unreduced $\mathrm{Pt}$ oxide could be responsible for the surface blocking, as the latter develops at the potentials, where $\mathrm{PtO}$ is unstable. It is worth mentioning that a potentiostatic reduction of oxygen on Pt covered with films made of a hydrocarbon based ionomer $6 \mathrm{~F}-40^{67}$ does exhibit the "ideal" behavior, i.e., a linear i vs. $\mathrm{t}^{-1 / 2}$ dependence at short reduction times is followed by a well-defined current plateau, ${ }^{68}$ which indicates the lack of Pt surface blocking phenomena. This fact is likely associated with a significantly less flexible backbone of $6 \mathrm{~F}-40$ compared to that of Nafion.

The lack of a common reference point, corresponding to the hypothetical undistorted ORR under all experimental conditions employed, makes it difficult to use any single parameter as the measure of ORR inhibition at different temperatures and humidities. The observed trends in half wave potentials, differences (hysteresis) between forward and reverse voltammetric scans, and the slopes of voltammograms (Fig. 8) indicate that ORR inhibition increases with both temperature and relative humidity. Similar effects of temperature on ORR at the Pt/recast Nafion interface and $100 \%$ RH were observed previously. ${ }^{38}$ The effect is opposite to what would be expected for a thermally activated process like oxygen reduction, but it correlates with the hydrogen UPD suppression irrespective of whether the latter is induced by temperature or humidity changes (Figs. 4 and 8). As concluded for hydrogen UPD, the temperature driven changes in ORR kinetics could hardly originate from the adsorption of common impurities. Also, any potentially unreduced $\mathrm{Pt}$ oxide remaining on the surface at the ORR potentials could not be responsible for the observed phenomena. If the oxide could no longer be reduced, a cathodic shift of the ORR wave would be observed rather than a progressive ORR inhibition (Fig. 8 and 10). Similarly, ORR would be progressively accelerated rather than inhibited, if the oxide could be eventually reduced, whereas the opposite is observed (Figs. 8 and 10).

The unexpected inhibition of ORR on Nafion coated Pt in high humidity environments prompted us to explore the effect of liquid water on ORR on Pt/Nafion interface. In the experiment, a drop of deionized water was deposited onto a film-covered UME, but away

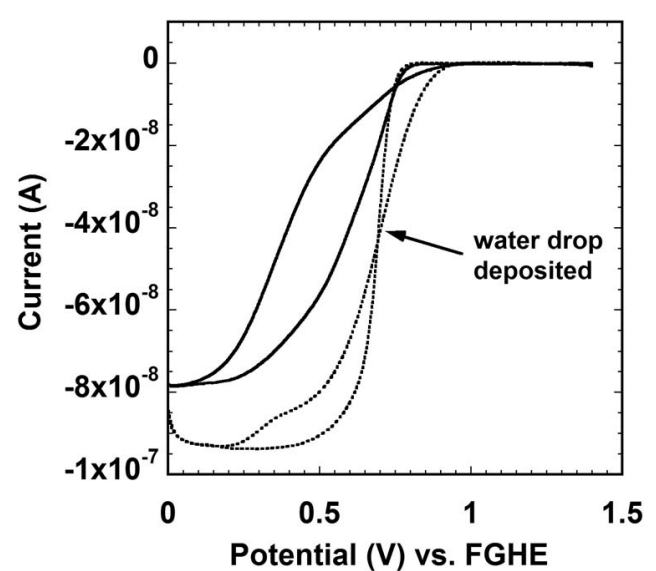

Figure 11. Background corrected voltammograms of oxygen on a $100 \mu \mathrm{m} \mathrm{Pt}$ UME covered with $13.5 \mu \mathrm{m}$ thick Nafion film at $100 \%$ RH before (solid line) and after (dotted line) the deposition of a drop of water onto the tip of the electrode (see text for procedure). RH $100 \%$. Temperature $20^{\circ} \mathrm{C}$.

from its center in order not to obstruct oxygen transport through the water layer. As demonstrated in Fig. 11, the full hydration of Nafion resulted in a much steeper ORR voltammogram, i.e., it significantly reduced the ORR inhibition and also improved the oxygen transport (the limiting current increase). This result strongly supports our previous conclusions that neither impurities nor unreduced Pt oxide are responsible for the observed ORR inhibition, since no dramatic changes in their respective electrode kinetics can result from rather moderate change in the bulk Nafion hydration. The improvement in oxygen transport results from the increase in volume fraction of hydrated hydrophilic component of Nafion, which is largely responsible for oxygen diffusion. ${ }^{65} \mathrm{On}$ the other hand, the influence of liquid water on the ORR kinetics bares close similarity to the known effect of liquid water on the surface structure of Nafion. ${ }^{47}$ The effect is linked to the Schroeder paradox, i.e., the inability of Nafion to achieve the state of full hydration at $100 \% \mathrm{RH}$ in absence of liquid water due to the hydrophobic component occupying the solid/gas interface. The surface structure of Nafion in contact with liquid water is open, i.e., both hydrophilic and hydrophobic fragments can be found on the surface and the polymer is fully hydrated. Therefore, we conclude that the phenomenon shown in Fig. 11 must have a very similar origin.

In summary, ORR is weakly inhibited at very low humidities and when Nafion is fully hydrated (equilibrated with liquid water), whereas the strongest ORR inhibition occurs at intermediate levels of hydration. Given the lack of a strictly quantitative measure of ORR inhibition at different humidities, it is impossible to exactly determine the humidity, where the inhibition is strongest, but its maximum most likely occurs at $60 \% \leq \mathrm{RH} \leq 100 \%$.

Oxygen reduction on Pt-black-covered surface.- Oxygen reduction on Pt-black was studied exclusively at $100 \%$ RH. As seen in Fig. 12, ORR at the Pt black/Nafion interface occurs at significantly lower overpotentials than those measured for smooth interfaces (Fig. 8d). The apparent lack of ORR inhibition at the "nanostructured" $\mathrm{Pt} / \mathrm{Nafion}$ interface indicates that the phenomena responsible for ORR inhibition on smooth electrodes are either non-existent or significantly slowed down at platinized electrodes. This finding correlates with the independence of hydrogen adsorption charges of the scan rate for such electrodes. In the absence of time dependent blocking of Pt surface, even if a fraction of Pt black surface area is inaccessible, there are still very numerous active $\mathrm{Pt}$ sites available to support ORR.

So far, the influence of the state of Pt surface on the interfacial morphology of Nafion and its effects on ORR have been demonstrated exclusively by the results of dynamic experiments with different time constraints and at various temperatures and humidities, but without consideration of other experimental conditions, which may also affect 


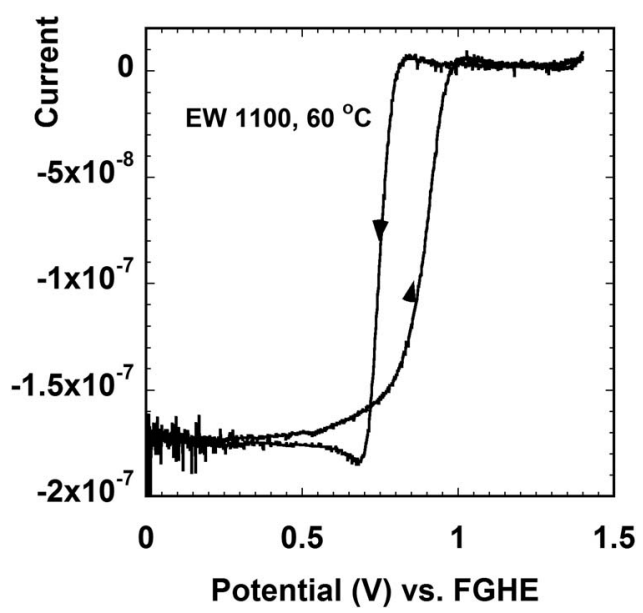

Figure 12. Background corrected voltammogram of oxygen on a platinized $100 \mu \mathrm{m}$ Pt UME covered with $13.5 \mu \mathrm{m}$ Nafion film at $100 \% \mathrm{RH}$ and $60^{\circ} \mathrm{C}$. Roughness factor before film deposition - 170 .

the observed phenomena. Some of these conditions are addressed in the following sections of the manuscript.

ORR on a smooth Pt surface - effects of film thickness and preparation method.- As mentioned in the Experimental section, the quick evaporation of Nafion solution in air produced non-uniform films with complex morphology. The ORR voltammograms for such films were rather irreproducible and had complex shapes, e.g. current minima. As the majority of such films were obtained using less than the standard amount of $8 \mu \mathrm{l}$ of Nafion solution (see Experimental section), the complex ORR voltammograms were attributed in the past to the smaller thickness of films produced in air and the resulting increase in water generation. ${ }^{69}$ The experiments in this section address more fully the effects of film thickness and preparation methods on ORR voltammetry.

Figure 13 shows ORR voltammogram recorded for Nafion films of different thickness. As the limiting current of oxygen reduction is approximately inversely proportional to the film thickness, ${ }^{70}$ the voltammograms in Fig. 13 have been normalized against the limiting current. Figure 13 demonstrates that the only effect of decreased film thickness is a small cathodic shift of the ORR wave. Even though ultramicroelectrodes were used in the study, we believe that the observed

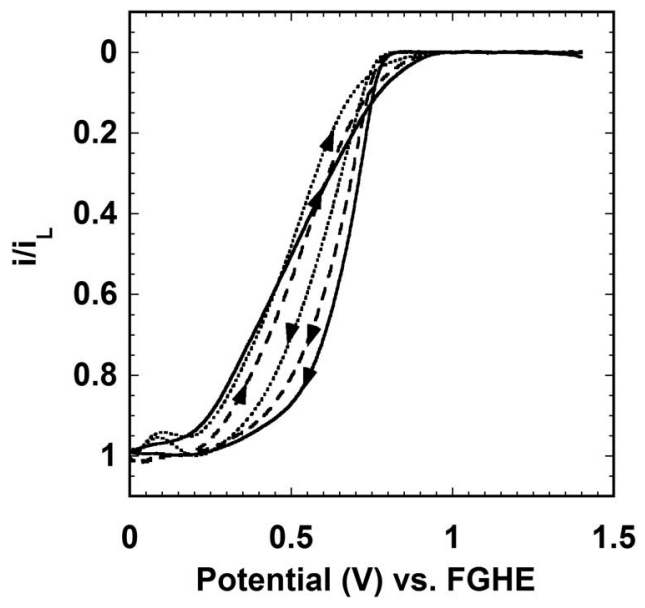

Figure 13. Background corrected voltammograms of oxygen on a $100 \mu \mathrm{m}$ Pt UME covered with Nafion films of different thickness normalized against the limiting current. RH $100 \%$. Temperature $20{ }^{\circ} \mathrm{C}$. Scan rate $5 \mathrm{mV} \mathrm{s}^{-1}$. Film thickness: $13.5 \mu \mathrm{m}$ (solid line); $2.0 \mu \mathrm{m}$ (dashed line); $0.7 \mu \mathrm{m}$ (dotted line). small cathodic shift results predominantly from the uncompensated ohmic drop (iR) in the experiments involving thinner $(0.7 \mu \mathrm{m}$ and $2.0 \mu \mathrm{m}$ ) films. Unfortunately, the actual iR drop or the film resistance could not be reliably measured for this or any other experiment involving smooth Pt/Nafion interfaces due to: i) the insufficiently long time scale of the dynamic phenomena observed (e.g., Fig. 9 and Fig. 10) to perform an undistorted resistance measurement and ii) an excessive noise in the attempted AC measurements in spite of using a Faraday cage. However, one can easily demonstrate that the ohmic drop in the experiment with the thickest film (Fig. 13), such as those used in virtually all other experiments, was negligible. While the flux of (uncharged) oxygen during the reaction is predominantly perpendicular to the electrode surface, the electric current between the counter and the working electrode flows in the direction predominantly parallel to the surface, i.e., from the electrode center to its perimeter, where the counter electrode is located. Hence, the resistance responsible for the $\mathrm{iR}$ drop is that determined by the film cross section perpendicular to the film surface, which is inversely proportional to the film thickness. The difference in thickness between the thickest $(13.5 \mu \mathrm{m})$ and the thinnest $(0.7 \mu \mathrm{m})$ film employed implies that the thicker film should have $\sim 20$ times lower resistance $(13.5 \mu \mathrm{m} / 0.7 \mu \mathrm{m} \approx 20)$. The currents measured at the respective half wave potentials $\left(\mathrm{E}_{1 / 2}\right)$ in these experiments (not shown in Fig. 13) remained in the ratio of $8.5(0.7 \mu \mathrm{m})$ to $1(13.5 \mu \mathrm{m})$. If it is assumed that both voltammograms are affected proportionally, one can conclude, based on the above numbers and the observed $\sim 100 \mathrm{mV}$ shift of $E_{1 / 2}$ (Fig. 13), that the ohmic drop for the thinnest film was $\sim 100 \mathrm{mV}$ but did not exceed $0.6 \mathrm{mV}$ for the thickest $(13.5 \mu \mathrm{m})$ film. Somewhat higher iR drops would be expected for less hydrated films $\left(\mathrm{RH}<100 \%\right.$, temperature $\left.>20^{\circ} \mathrm{C}\right)$, but our results (e.g. Fig. 8a vs. 8d) indicate that iR drop is insufficient to explain the dynamic phenomena described above. The observed surface blockage affects the charge transfer resistance, but is not expected to noticeably affect the conductivity of the bulk Nafion film, i.e., it does not produce an uncompensated ohmic drop. The actual effects of uncompensated resistance for the thin films (Fig. 13) may be even smaller, if the water generated by ORR facilitates the process of interfacial ionomer restructuring. While such an effect is difficult to quantify, the results of our study of hydrogen peroxide generation at smooth Pt/Nafion interfaces ${ }^{71}$ support such a conclusion.

Figure 14 shows ORR voltammograms recorded for Nafion films prepared or equilibrated under non-standard conditions, when oxygen/air was present during either the film evaporation, conditioning or equilibration. The top three voltammograms in Fig. 14 were

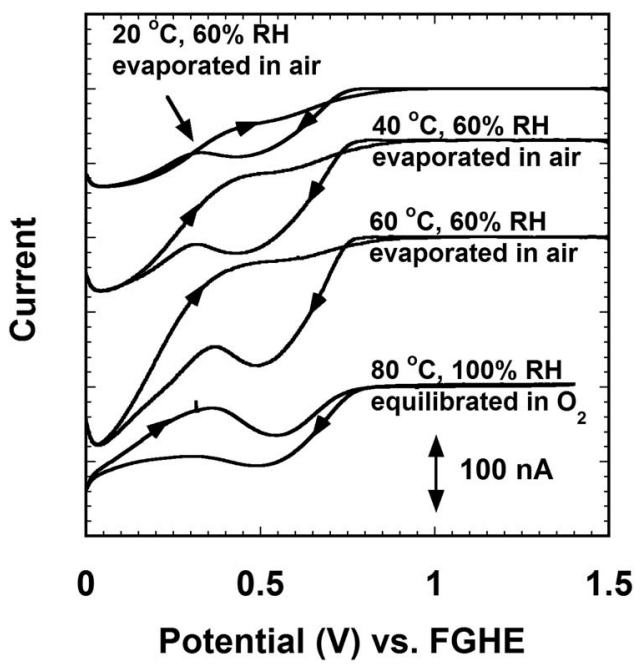

Figure 14. Background corrected voltammograms of oxygen on a $100 \mu \mathrm{m} \mathrm{Pt}$ UME covered with Nafion films produced and equilibrated using non-standard procedures (see text). Scan rate $5 \mathrm{mV} \mathrm{s}^{-1}$. Film thickness: $13.5 \mu \mathrm{m}$ (bottom voltammogram); unknown (top three voltammograms). No background correction applied to the bottom voltammogram. 
recorded for Nafion EW 1100 films made by dipping UME in a 5\% Nafion solution and evaporating in air the solution that accumulated on the electrode tip. The films were equilibrated for $\sim 1$ hour in $60 \%$ $\mathrm{RH}$ argon, after which background voltammograms were recorded. After subsequent 1-2 hour film equilibration in $60 \%$ RH oxygen, ORR voltammograms were recorded. The bottom voltammogram in Fig. 14 was recorded at $80{ }^{\circ} \mathrm{C}$ and $100 \% \mathrm{RH}$ for a $13.5 \mu \mathrm{m}$ thick Nafion EW 1100 film prepared in the standard way, i.e., by slow evaporation of Nafion solution followed by $\sim 20$ hour "conditioning" in $10 \% \mathrm{RH}$ argon at ambient temperature (see Experimental section). However, instead of subsequent film equilibration in $100 \% \mathrm{RH}$ Ar at $80{ }^{\circ} \mathrm{C}$, the film was equilibrated for 8 hours in $100 \% \mathrm{RH}$ oxygen at $80^{\circ} \mathrm{C}$. A virtually identical voltammogram (not shown) was recorded after another 20 hours of the film equilibration in $100 \% \mathrm{RH}$ oxygen at $80{ }^{\circ} \mathrm{C}$.

There are two major differences between the voltammograms in Fig. 14 and those recorded for the films prepared/equilibrated according to the standard procedure (Fig. 8), which rigorously excluded oxygen during all steps but the measurement (Fig. 8). First of all, current maxima and minima are seen in the voltammograms in Fig. 14, whereas no similar features are present in the voltammograms in Fig. 8. Another difference becomes apparent at higher temperatures $\left(60-80{ }^{\circ} \mathrm{C}\right)$. While temperature increase leads to progressive ORR inhibition for films that underwent the standard preparation/equilibration procedure (Figs. 8c,d), the opposite is true in quite a wide potential range for the films that underwent the non-standard pretreatments, which involved a prolonged exposure of the electrode coated with liquid or solid Nafion to air or oxygen. As Nafion is quite resistant to oxidation, the different voltammetric behavior observed for such films can result from nothing else but the oxidation of either the Pt surface or alcohols present in the liquid Nafion suspension or both. In either case, the origins of the differences between the voltammograms shown in Figs. 8c,d and 14 can only be linked to the state of the Pt surface in these experiments, because any unreacted or partially oxidized alcohols not adsorbed on the Pt surface would evaporate during the prolonged electrode equilibration/conditioning at elevated temperatures. The adsorbed products of alcohol oxidation can only slow down the ORR (see Fig. 6, which demonstrates almost complete poisoning of a high surface area Pt right after the deposition of Nafion suspension). To the contrary, the onset of ORR for the film equilibrated in $100 \% \mathrm{RH}$ oxygen at $80{ }^{\circ} \mathrm{C}$ (Fig. 14) is much more positive (i.e., it demonstrates a faster charge transfer kinetics) than that observed for a virtually identical film equilibrated in $100 \% \mathrm{RH}$ argon at $80{ }^{\circ} \mathrm{C}$ (Fig. 8d). In conclusion, the better overall ORR kinetics for the film equilibrated in oxygen (Fig. 14) compared to that equilibrated in $\mathrm{Ar}$ (Fig. 8d) is predominantly caused by the oxide formed on the Pt surface during electrode equilibration in oxygen atmosphere. The state of the Pt surface during solution casting, evaporation and prolonged equilibration determines the more or less permanent but not necessarily equilibrium interfacial morphology of the Nafion film. For the film equilibrated in oxygen (Fig. 14), the "permanent" morphology involves the presence of the hydrophilic Nafion component at the interface with Pt covered with its hydrophilic oxide. On the other hand, the "permanent" morphology for the films equilibrated in Ar (Fig. 8) corresponds to the hydrophobic Nafion component occupying the interface with bare Pt. If the oxidation state of Pt surface significantly changes after the equilibration, a driving force to change the interfacial Nafion morphology appears. The driving force may be insufficient to guarantee the transition to a new low energy state for the entire film during relatively short voltammetric experiments, but may be strong enough to cause morphological changes involving only the ionomer molecules or their fragments in the vicinity of the surface. The dynamic changes in the voltammetry of Nafion coated Pt under various conditions reflect the localized changes in Nafion films morphology, whereas the film preparation and equilibration affect the initial state of the Nafion film, as demonstrated by the voltammograms shown in Fig. 14 and by neutron reflectivity. ${ }^{31}$

As indicated by the published FTIR data, ${ }^{13}$ the interfacial morphology of Nafion in contact with Pt surface develops quickly during evaporation of liquid Nafion suspension in air at ambient temperature. The time required for the equilibrium structure to develop in a film that already hardened may be significantly longer even at high temperature and $\mathrm{RH}$, which explains why the voltammogram recorded after eight hours of film equilibration in $100 \%$ RH oxygen at $80^{\circ} \mathrm{C}$ (Fig. 14) is different than those recorded for films equilibrated in $\mathrm{Ar}$ that underwent only the $10 \mathrm{~s}$ hold at $+1.4 \mathrm{~V}$ in oxygen atmosphere before voltammetry (Fig. 8d).

The slow kinetics of transitions between "permanent" Nafion structures typical for the oxide-free (Fig. 8) and oxide-covered (Fig. 14) platinum surfaces implies that the effects of surface interactions on the structure of ionomer have a long range character, since the reorientation of very surface atoms and bonds is fast (Fig. 9). The long range effects of the state of Pt surface on Nafion morphology may in part result from interfacial charge separation phenomena (electrical double layer formation) at these interfaces, which may lead to significant ordering (layering) ${ }^{72}$ of the ionomer chains.

\section{Conclusions}

The study demonstrated that the interfacial morphology of cast Nafion films on platinum depends on the oxidation state of the Pt surface. The thermodynamically preferred morphologies of the interfaces of surface oxidized and bare Pt with partially hydrated Nafion correspond respectively to the hydrophilic and hydrophobic Nafion components occupying the interface. The blocking of bare $\mathrm{Pt}$ surface by the hydrophobic component of Nafion leads to significant inhibition of ORR, but the effect virtually disappears in presence of liquid water, i.e., when Nafion is fully hydrated. Transitions between the two morphologies are possible as a result of changes of the oxidation state of $\mathrm{Pt}$ as long as Nafion retains its substantial mobility, i.e., for cast films on smooth Pt surfaces (Fig. 15), but they are significantly slowed down at rough interfaces and in preformed membranes. The rate of the transitions (presumably also their driving force) and the extent of ORR inhibition reach their maxima at high relative humidities $(60 \%-100 \%)$, decrease at low humidities and become immeasurable in presence of liquid water.

While fundamental aspects of these studies are valid for the model system investigated, the highest interest in these studies is likely to be generated by the electrochemical device community (fuel cells, electrolyzers), and how these results relate to the polymer electrolyte/Pt interface in operating devices. We have put some of our results in context that may be relevant to the fuel cell community, but it is also important to point out that we have employed model systems substantially different than those used in devices. The polymer film thicknesses probed are many orders of magnitude thicker than those coating particles within electrode structures, and have been applied to Pt-only, relatively flat substrates (even when roughened). This contrasts typical electrodes where surface areas are high and dominated by carbon particles with small Pt nanoparticles, and water generation rates normalized by total polymer electrolyte are significantly higher. As demonstrated by rotating ring disk electrode studies, ${ }^{73}$ the quality and the apparent activity of carbon supported Pt catalysts strongly depends on the quantity of Nafion used in the catalyst layer. Therefore, care must be taken when interpreting the results presented in terms of device impact. Still, the data presented allows a model Pt/polymer electrolyte system to be probed in ways otherwise not possible. Our results clearly show the dynamic nature or the polymer interface and how interactions at this interface impact distances far away from the interface. They add to a clearer understanding of the impacts of polymer electrolytes on catalyst performance and electrode properties.

Finally, a comment seems necessary on the demonstrated affinity of hydrophobic component of Nafion to bare Pt surface. While the finding seems to remain at odds with the documented presence of a monolayer of water on Pt surface in aqueous media, ${ }^{74}$ recent studies ${ }^{13,20,75}$ provide a compelling evidence that unoxidized Pt surfaces have a hydrophobic character even if covered by a monolayer of water. ${ }^{75}$ The affinity of the hydrophobic Nafion component to bare Pt surface can also have similar origins to those for the common adsorption of organic, 

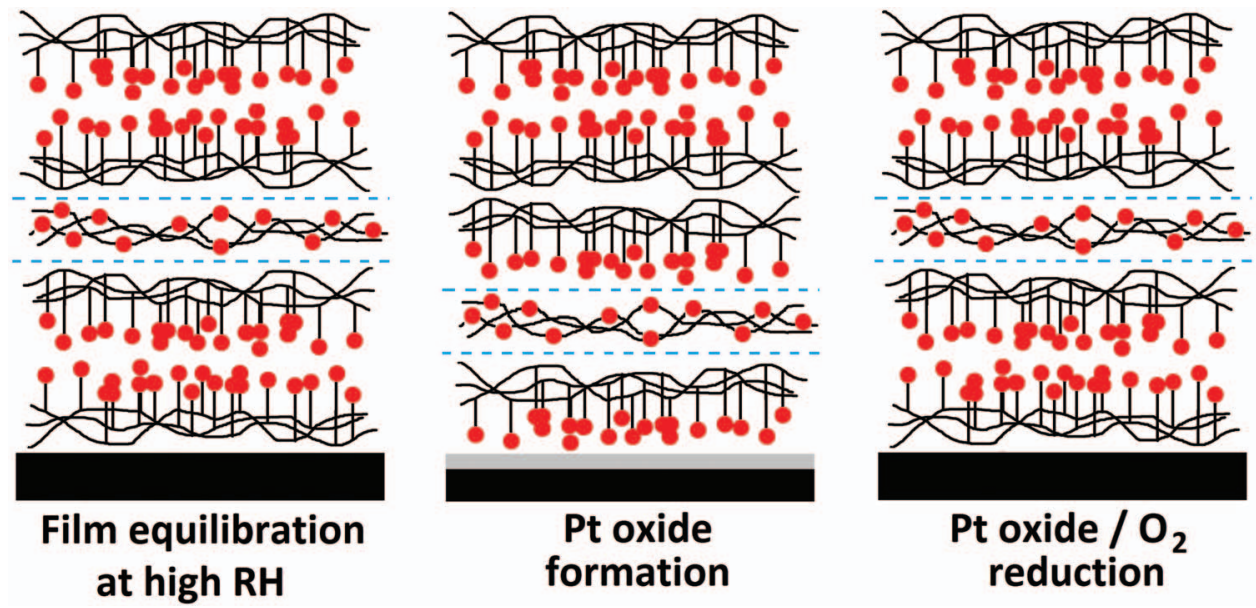

Figure 15. Schematic representation of the interface between cast Nafion and smooth Pt surface at different stages of electrochemical experiments. The black lines represent the hydrophobic backbone and the red dots hydrophilic/hydrated sulfonic groups. The horizontal blue lines mark the transition between the interfacial and bulk ionomer structures.

e.g., aliphatic molecules on polarizable metal surfaces in aqueous electrolytes. $^{76}$

\section{Acknowledgment}

Financial support is provided by the U.S. Department of Energy, Office of Energy Efficiency Renewable Energy, through contract no. DE-AC52-06NA25396 to the Los Alamos National Laboratory and through contract no. DE-AC36-08GO28308 to the National Renewable Energy.

\section{References}

1. C. M. Johnston, P. Piela, and P. Zelenay, in Handbook of Fuel Cells, vol. 5, Chapter 4, pp. 48, W. Vielstich, H. A. Gasteiger, and H. Yokokawa, Editors, Wiley \& Sons, Chichester, United Kingdom.

2. P. H. Matter, E. J. Biddinger, and U. S. Ozkan, Catalysis, 20, 338 (2007) and references therein.

3. M. Chisaka and H. Daiguji, Electrochem. Comm., 8, 1304 (2006) and references therein

4. V. Di Noto, E. Negro, S. Polizzi, K. Vezzù, L. Toniolo, and G. Cavinato, Int. J. Hydrogen Energy, 39, 2812 (2014).

5. E. Negro, S. Polizzi, K. Vezzù, L. Toniolo, G. Cavinato, and V. Di Noto, Int. J. Hydrogen Energy, 39, 2828 (2014).

6. E. Negro, K. Vezzù, F. Bertasi, P. Schiavuta, L. Toniolo, S. Polizzi, and V. Di Noto, ChemElectroChem., 1, 1359 (2014)

7. M. Schulze, N. Wagner, T. Kaz, and K. A. Friedrich, Electrochim. Acta., 52, 2328 (2007).

8. E. Antolini, J. Mat. Sci., 38, 2995 (2003) and references therein.

9. J. Shan and P. G. Pickup, Electrochim. Acta, 46, 119 (2000).

10. H. Xu, E. Brosha, F. Garzon, F. Uribe, M. Wilson, and B. Pivovar, ECS Trans., 11 (1), 383 (2007)

11. M. S. McGovern, E. C. Garnett, C. Rice, R. I. Masel, and A. Wieckowski, J. Power Sources, 115, 35 (2003).

12. A. Ohma, K. Fushinobu, and K. Okazaki, Electrochim. Acta, 55, 8829 (2010).

13. K. Kanamura, H. Morikawa, and T. Umegaki, J. Electrochem. Soc., 150, A193 (2003).

14. E. Aleksandrova, R. Hiesgen, K. Andreas Friedrich, and E. Roduner, Phys. Chem. Chem. Phys., 9, 2735 (2007).

15. K. C. Neyerlin, H. A. Gasteiger, C. K. Mittelsteadt, J. Jorne, and W. Gu, J. Elec trochem. Soc., 152, A1073 (2005).

16. H. Xu, Y. Song, H. Russel Kunz, and J. M. Fenton, J. Electrochem. Soc., 152, A1828 (2005)

17. T. D. Gierke, G. E. Munn, and F. C. Wilson, J. Polym. Sci. Polym. Phys. Edn., 19, 1687 (1981)

18. W. Y. Hsu and T. D. Gierke, J. Membr. Sci. 13, 307 (1983).

19. P. Aldebert, B. Dreyfus, G. Gebel, N. Nakamura, M. Pineri, and F. Volino, J. Phys. France 49, 2101 (1988)

20. G. Gebel, (2000), Polymer, 41, 5829 (2000)

21. L. Rubatat, A. L. Rollet, G. Gebel, and O. Diat, Macromolecules, 354050 (2002)

22. V. Barbi, S. S. Funari, R. Gehrke, N. Scharnagl, and N. Stribeck, Polymer, 44, 4853 (2003).

23. P. C. van der Heijden, L. Rubatat, and O. Diat, Macromolecules, 37, 5327 (2004).

24. L. Rubatat, G. Gebel, and O. Diat, Macromolecules, 37, 7772 (2004).

25. G. Gebel and O. Diat, Fuel Cells, 5, 261 (2005).
26. L. Rubatat and O. Diat, (2007), Macromolecules 40, 9455 (2007).

27. K. Schmidt-Rohr and Q. Chen, Nature Materials, 7, 75 (2008).

28. D. Malevich, V. Zamlynny, S.-G. Sun, and J. Lipkowski, Z. Phys. Chem., 217, 513 (2003).

29. Y. Ayato, K. Kunimatsu, M. Osawa, and T. Okada, J. Electrochem. Soc., 153, A203 (2006).

30. D. Wood, J. Chlistunoff, E. Watkins, P. Atanassov, and R. Borup, ECS Trans., 3(1), 1011 (2006)

31. D. L. Wood III, J. Chlistunoff, J. Majewski, and R. L. Borup, (2009), J. Am. Chem Soc., 131, 18096 (2009)

32. E. J. Lamas and P. B. Balbuena, Electrochim. Acta, 51, 5904 (2006).

33. J. Liu, M. E. Selvan, S. Cui, B. J. Edwards, D. J. Keffer, and W. V. Steele, J. Phys. Chem. C, 112, 1985 (2008).

34. A. Parthasarathy, C. R. Martin, and S. Srinivasan, J. Electrochem. Soc., 138, 916 (1991).

35. A. Parthasarathy, B. Dave, S. Srinivasan, A. J. Appleby, and C. R. Martin, J. Elec trochem. Soc., 139, 1634 (1992).

36. A. Parthasarathy, S. Srinivasan, A. J. Appleby, and C. R. Martin, J. Electrochem. Soc., 139, 2530 (1992)

37. A. Parthasarathy, S. Srinivasan, A. J. Appleby, and C. R. Martin, J. Electrochem. Soc., 139, 2856 (1992)

38. F. A. Uribe, T. E. Springer, and S. Gottesfeld, J. Electrochem. Soc., 139, 765 (1992)

39. F. N. Büchi, M. Wakizoe, and S. Srinivasan, J. Electrochem. Soc., 143, 927 (1996).

40. V. I. Basura, P. D. Beattie, and S. Holdcroft, J. Electroanal. Chem., 458, 1 (1998).

41. P. D. Beattie, V. I. Basura, and S. Holdcroft, J. Electroanal. Chem., 468, 180 (1999).

42. V. I. Basura, C. Chuy, P. D. Beattie, and S. Holdcroft, J. Electroanal. Chem., 501, 77 (2001).

43. S. Mitsushima, N. Araki, N. Kamiya, and K. Ota, J. Electrochem. Soc., 149, A1370 (2002).

44. L. Zhang, C. Ma, and S. Mukerjee, Electrochim. Acta, 48, 1845 (2003)

45. L. Zhang, C. Ma, and S. Mukerjee, J .Electroanal. Chem., 568, 273 (2004).

46. Z. Xie and S. Holdcroft, J. Electroanal. Chem., 568, 247 (2004).

47. V. Freger, J. Phys. Chem. B, 113, 24 (2009).

48. J. A. Elliott, S. Hanna, J. N. Newton, A. M S. Elliott, and G. E. Cooley, Polymer Eng. Sci., $228(2006)$

49. C. F. Zinola, A. M. Castro Luna, W. E. Triaca, and A. J. Arvia, J. Appl. Electrochem., 24, 119 (1994).

50. J. A. Dura, V. S. Murthi, M. Hartman, S. K. Satija, and C. F. Majkrzak, Macromolecules, 2009, 42 (13), 4769.

51. S. A. Eastman, S. Kim, K. A. Page, B. W. Rowe, S. Kang, C. L. Soles, and K. G. Yager, Macromolecules, 45, 7920 (2013).

52. H. F. M. Mohamed, S. Kuroda, Y. Kobayashi, N. Oshima, R. Suzuki, and A. Ohira, Phys. Chem. Chem. Phys., 15, 1518 (2013)

53. G. C. Abuin, M. C. Fuertes, and H. R. Corti, J. Membr. Sci., 428, 507 (2013).

54. H. Hanawa, K. Kunimatsu, M. Watanabe, and H. Uchida, J. Phys. Chem. C, 116, 21401 (2012)

55. Los Alamos National Laboratory is located at an elevation of $2100 \mathrm{~m}$ and the atmospheric pressure is $\sim 78 \%$ of that at the sea level. As a result of the lower pressure, the potential of any hydrogen reference potential is more positive by $3 \mathrm{mV}$ than that measured at the sea level. Similarly, the solubility of oxygen in Nafion and the respective oxygen reduction currents are $78 \%$ of those expected at the sea level, assuming applicability of Henry's law for the oxygen/Nafion system.

56. T. A. Zawodzinski Jr, S. Gottesfeld, S. Shoichet, and T. J. McCarthy, J. Appl. Electrochem., 23, 86 (1993).

57. P. Choi and R. Datta, J. Electrochem. Soc., 150, E601 (2003) and references therein. 
58. L. M. Onishi, J. M. Prausnitz, and J. Newman, J. Phys. Chem. B., 111, 10166 (2007) and references therein.

59. A. Zolfaghari and G. Jerkiewicz, J. Electroanal. Chem., 420, 11 (1997).

60. A. Zolfaghari and G. Jerkiewicz, J. Electroanal. Chem., 422, 1 (1997).

61. A. Zolfaghari, M. Chayer, and G. Jerkiewicz, J. Electrochem. Soc., 144, 3034 (1997)

62. A. Zolfaghari and G. Jerkiewicz, J. Electroanal. Chem., 467, 177 (1999).

63. Z. Radovic-Hrapovic and G. Jerkiewicz, J. Electroanal. Chem., 499, 61 (2001).

64. L. A. Zook and J. Leddy, Anal. Chem., 68, 3793 (1996).

65. S. Gottesfeld and T. A. Zawodzinski in Advances in Electrochemical Science and Engineering, vol. 5, 1st ed, R. C. Alkire, H. Gerischer, D. M. Kolb, and C. W. Tobias, editors, p. 195, Wiley-VCH, Weinheim (1997) and references therein.

66. D. Shoup and A. Szabo, J. Electroanal. Chem., 140, 237 (1982).
67. Y. S. Kim, B. Einsla, M. Sankir, W. Harrison, and B. S. Pivovar, Polymer, 47, 4026 (2006).

68. J. Chlistunoff, J. Power Sources, 245, 203 (2014).

69. J. Chlistunoff, F. Uribe, and B. Pivovar, ECS Trans., 1(6), 137 (2006).

70. J. Chlistunoff, F. Uribe, and B. Pivovar, ECS Trans., 2(8), 37 (2007).

71. J. Chlistunoff and B. Pivovar, ECS Trans., 11(1), 1115 (2007).

72. Z. Li and J. Wu, J. Phys. Chem. B, 110, 7473 (2006) and references therein

73. Y. Garsany, O. A. Baturina, K. E. Swider-Lyons, and S. S. Kocha, Anal. Chem., 82, 6321 (2010).

74. P. A. Thiel and T. E. Madey, Surf. Sci. Rep., 7, 211 (1987) and references therein.

75. G. A. Kimmel, N. G. Petrik, Z. Dohnálek, and B. D. Kay, Phys. Rev. Lett., 95, 166102-1-166102-4 (2005).

76. J. O'M. Bockris, M. A. V. Devanathan, and K. Müller, Proc. Royal Soc. London. Ser A, Math. Phys. Sci., 274, 55 (1963). 